\title{
Efficacy and safety of intracoronary prourokinase during percutaneous coronary intervention in treating ST-segment elevation myocardial infarction patients: a randomized, controlled study
}

\author{
Yanqiang $\mathrm{Wu}^{1}$, Xianghua Fu ${ }^{1 *}$ (D), Qiang Feng ${ }^{2}$, Xinshun $\mathrm{Gu}^{1}$, Guozhen Hao ${ }^{1}$, Weize Fan ${ }^{1}$ and Yunfa Jiang ${ }^{1}$
}

\begin{abstract}
Background: Prourokinase is a single-chain plasminogen activator presenting with fewer hemorrhagic complications and reduced reocclusion rate compared with the conventional fibrinolytic agents in patients with coronary artery disease. However, prourokinase intracoronary injection during PCI for treating patients with STsegment elevation myocardial infarction (STEMI) is rarely investigated. Therefore, this study aimed to evaluate the efficacy and safety of intracoronary prourokinase during the percutaneous coronary intervention $(\mathrm{PCl})$ in treating STEMI patients.
\end{abstract}

Methods: Fifty STEMI patients who underwent primary PCI were consecutively enrolled and randomly assigned to intracoronary prourokinase group $(N=25)$ or control group $(N=25)$. During the primary PCl procedure, patients in the intracoronary prourokinase group received $10 \mathrm{ml}$ prourokinase injection, while patients in control group received $10 \mathrm{ml}$ saline injection as control. The primary endpoints were coronary physiological indexes, the secondary endpoints were angiographic assessments, myocardial infarct size/reperfusion assessment, cardiac function evaluations, major adverse coronary events (MACEs) and hemorrhagic complications. All patients were followed up for 3 months.

\footnotetext{
* Correspondence: dufang27481519@163.com

'Department of Cardiology, The Second Hospital of Hebei Medical University,

215 West Heping Road, Shijiazhuang 050000, China

Full list of author information is available at the end of the article
}

(c) The Author(s). 2020 Open Access This article is licensed under a Creative Commons Attribution 4.0 International License, which permits use, sharing, adaptation, distribution and reproduction in any medium or format, as long as you give appropriate credit to the original author(s) and the source, provide a link to the Creative Commons licence, and indicate if changes were made. The images or other third party material in this article are included in the article's Creative Commons licence, unless indicated otherwise in a credit line to the material. If material is not included in the article's Creative Commons licence and your intended use is not permitted by statutory regulation or exceeds the permitted use, you will need to obtain permission directly from the copyright holder. To view a copy of this licence, visit http://creativecommons.org/licenses/by/4.0/. The Creative Commons Public Domain Dedication waiver (http://creativecommons.org/publicdomain/zero/1.0/) applies to the data made available in this article, unless otherwise stated in a credit line to the data. 
(Continued from previous page)

Results: Post $\mathrm{PCl}$, the index of microcirculatory resistance (IMR) was decreased in intracoronary prourokinase group than that in control group (34.56 \pm 7.48 vs. $49.00 \pm 8.98, P<0.001)$, while no difference of coronary flow reserve (CFR) $(2.01 \pm 0.32$ vs. $1.88 \pm 0.23, P=0.267)$ or fractional flow reserve (FFR) $(0.89 \pm 0.05$ vs. $0.87 \pm 0.04, P=0.121)$ was found between the two groups. The thrombolysis in myocardial infarction myocardial perfusion grade (TMPG) $(P=$ 0.024), peak values of creatine kinase $(C K)(P=0.028)$, CK isoenzyme-MB (CK-MB) $(P=0.016)$, cardiac troponin I (CTnl) $(P=0.032)$ and complete ST-segment resolution $(S T R)(P=0.005)$ were better in intracoronary prourokinase group compared with control group. At 3-months post PCl, left ventricular ejection fraction (LVEF) and wall motion score index (WMSI) were higher, while left ventricular end-diastolic diameter (LVEDd) was lower in intracoronary prourokinase group compared with control group (all $P<0.05$ ). There was no difference in hemorrhagic complication or total MACE between the two groups.

Conclusion: Intracoronary prourokinase during $\mathrm{PCl}$ is more efficient and equally tolerant compared with $\mathrm{PCl}$ alone in treating STEMI patients.

Trial registration: Chinese Clinical Trial Registry ChiCTR1800016207. Prospectively registered.

Keywords: STEMI, PCl, Prourokinase, Efficacy, Safety

\section{Background}

ST-segment elevation myocardial infarction (STEMI), united by persistent ischemic chest pain over $20 \mathrm{~min}$, the ST-segment elevation and the increase of myocardial necrosis biomarkers, is still a rather prevalent cause of mortality and morbidity in clinical practice [1]. Percutaneous coronary intervention (PCI) has evolved as the mainstay of STEMI management since its first introduction four decades ago, and with the development of new technology, patients' prognosis has been primarily advanced [2]. However, apart from all the benefits that PCI brings to the patients attacked by STEMI, there also exist hemorrhagic and cardiovascular events, not to mention that in patients with a favorable outcome after PCI, a considerable proportion of 30-day and 1-year mortality still could be seen [3]. Therefore, more efforts must be made in the context of PCI treatment in STEMI patients.

Fibrin specific thrombolytic agents have been extensively used for thrombolysis in patients with STEMI, among which prourokinase is a single-chain plasminogen activator presenting with fewer hemorrhagic complications and reduced reocclusion rate in patients compared with the conventional fibrinolytic agents [4, 5]. Although very promising, prourokinase is still not a frequent drug used for STEMI patients due to the lack of evidence. To be specific, there are very limited studies investigating efficacy and safety of prourokinase in STEMI, among which, a large randomized clinical trial states that $20 \mathrm{mg}$ prourokinase intravenously injection followed by $30 \mathrm{mg}$ prourokinase intravenous infusion within $30 \mathrm{~min}$ is effective and tolerable in patients with STEMI [6]. Thus, we presumed that prourokinase might also be efficient and safe during PCI in treating patients with STEMI.
In addition, not only macrovascular but also microvascular is critical in the coronary disease, and the latter has been demonstrated to be even more crucial, hence, the indexes indicating coronary flow determined by the microvascular function, including index of microcirculatory resistance (IMR), coronary flow reserve (CFR) and fractional flow reserve (FFR) are important for assessing the function recovery of patients post PCI procedure [7, 8]. Besides, the assessment of indexes indicating angiographic status, myocardial infarct size, myocardial reperfusion and cardiac function are critical for the management of patients post PCI as well.

Therefore, this study evaluated the efficacy and safety of intracoronary prourokinase during PCI in treating STEMI by assessing the indexes indicating cardiac function and adverse events, respectively.

\section{Methods \\ Patients}

Between June 2017 and December 2017, 50 STEMI patients underwent primary PCI in the Second Hospital of Hebei Medical University were consecutively enrolled in the present study. Inclusion criteria were as follows: (1) persistent chest pain more than $30 \mathrm{~min}$, and ST-segment elevation with the cut-off $\mathrm{J}$ points $\geq 1 \mathrm{~mm}$ in standard leads or $\geq 2 \mathrm{~mm}$ in contiguous precordial leads on electrocardiograph (ECG); (2) progressive ischemic chest pain or unstable hemodynamics with ST-segment elevating when the onset time reached $12 \sim 24 \mathrm{~h}$; (3) age more than 18 years; (4) symptom onset within $6 \mathrm{~h}$ before randomization, and intention to undergo primary PCI. Patients were excluded if they presented with (1) suspected aortic dissection, infective endocarditis, significant valvular heart disease, or cardiac shock, (2) hematologic diseases, hemorrhagic diseases or bleeding 
propensity, (3) history of cerebral hemorrhage, subarachnoid hemorrhage, intracranial tumors, cerebral vascular malformations, other stroke or cerebrovascular events known within 3 months, (4) history of bleeding, trauma and visceral surgery within 4 weeks, (5) previous coronary artery bypass grafting (CABG), (6) severe head closed trauma or facial trauma within 3 months, (7) severe liver and kidney dysfunction, malignant tumor, acute inflammatory diseases, (8) pregnant women, (9) contraindications to prourokinase, aspirin, ticagrelor and heparin. Besides, angiographic exclusions included the left main disease with stenosis more than $50 \%$, no obvious thrombus burden, severe coronary tortuosity or significant distal stenosis, and chronic total occlusion.

\section{Ethics statement}

The study protocol was approved by the Ethics Committee of the Second Hospital of Hebei Medical University, and the study was conducted in accordance with the Declaration of Helsinki and Good Clinical Practice guidelines. Written informed consents were provided by all study participants.

\section{Randomization, grouping and interventions}

Before primary PCI, all the eligible patients were randomly assigned to the intracoronary prourokinase group $(N=25)$ or control group $(N=25)$ as a 1:1 ratio, with a block randomization method. Random sequence was created by SAS 9.2 (SAS Institute, Inc., Cary, North Carolina, USA) software, and the assignment of patients was performed by a nurse who was not involved in the subsequent study. During the primary PCI, for patients in the intracoronary prourokinase group, $10 \mathrm{mg}$ prourokinase (Shanghai Tian Shi Li Pharmaceutical Co, Ltd., Shanghai, China) were administered to the infarction related artery (IRA) through the thrombus aspiration catheter; as for the patients in the control group, $10 \mathrm{ml}$ saline was injected into the IRA by the thrombus aspiration catheter. In addition, the study flow of this study was presented in Fig. 1.

\section{Primary $\mathrm{PCl}$ procedures}

After admission, all patients were administered with 300 $\mathrm{mg}$ aspirin and $180 \mathrm{mg}$ ticagrelor. Angiotensinconverting enzyme inhibitors or angiotensin receptor blockers were administered to patients who had a systolic blood pressure (SBP) $>120 \mathrm{mmHg}$, and ß-blocker were given to patients with heart rate $(\mathrm{HR})>60 \mathrm{bpm}$ or there was not wet rale in the auscultation of the lungs. Moreover, statins were given to all patients. All patients were given an initial bolus of $5000 \mathrm{U}$ of intravenous heparin or weight-based dosage according to the discretion of the operator, with additional dose to keep the act time up to $250 \sim 300 \mathrm{~s}$. Tirofiban was administered according to the discretion of the operator as well. Coronary angiography was performed for all patients. All patients were punctured through the forearm approach (radial artery or ulnar artery). A 6F coronary guiding catheter was used to engage the culprit coronary artery, the pressuretemperature guide wire was calibrated in vitro, then was sent to the ostium of the coronary artery to be calibrated inside, which made the distal arterial pressure ( $\mathrm{Pd}$ ) equal to the proximal aortic pressure $(\mathrm{Pa})$. Then the wire was sent to pass across the stenosis into the target distal third of the vessel, after that, the Export AP thrombus catheter (Medtronic Cardiovascular, Santa Rosa, California, USA) was used for thrombus aspiration (repeated 3-5 times). Then the thrombus aspiration catheter was sent to the distal of the lesion. For intracoronary prourokinase group, through the thrombus aspiration catheter, prourokinase $(10 \mathrm{mg}$ with saline diluted into $10 \mathrm{ml}$ ) was slowly administered until the end of the catheter left the proximal of the occluded lesion. And in the control group, $10 \mathrm{ml}$ saline was injected into the IRA by the thrombus aspiration catheter. Finally, stent implantation was performed when patients' extent of vascular stenosis was more than $75 \%$. All procedural characteristics were recorded in detail, and thrombus grade was sorted according to the thrombolysis in myocardial infarction (TIMI) criteria as follows [9]: grade 0, no thrombus present; grade 1, possible thrombus present with angiographic characteristics of reduced contrast density, grade 2, explicit thrombus with dimension $\leq 1 / 2$ artery diameter; grade 3 , thrombus with the linear dimension $>1 / 2$, but less than two artery diameter; grade 4 , thrombus with dimension $\geq 2$ artery dimension; grade 5 , total occlusion.

\section{Coronary physiological measurements}

Coronary physiological indexes including the index of IMR, CFR and FFR were measured after primary PCI. Briefly, $3 \mathrm{ml}$ normal saline was injected into coronary artery through the guide catheter at room temperature, and if the temperature decreased less than 2 degrees, the conduction time of the baseline $\left(\mathrm{T}_{\mathrm{mn}}\right)$ was measured, which was repeated 3 times to produce three reproducible and consistent thermodilution curves. If the difference between one of the $\mathrm{T}_{\mathrm{mn}}$ and the other two measurements was above $30 \%$, it was performed again. The average of the three $T_{m n}$ was taken as the mean baseline transit time $\left(\mathrm{bT}_{\mathrm{mn}}\right)$. In addition, Adenosine Disodium Triphosphate (Guangdong Nan Guo Pharmaceutical Co, Ltd., Zhanjiang, Guangdong, China) was given to induce the maximum hyperemia status of microcirculation through the median vein of the elbow, which was confirmed by the decrease of $15 \mathrm{mmHg}$ as the SBP. Another three thermodilution curves were produced and the average conduction time was hyperemic $\mathrm{T}_{\mathrm{mn}}\left(\mathrm{hT}_{\mathrm{mn}}\right)$. 


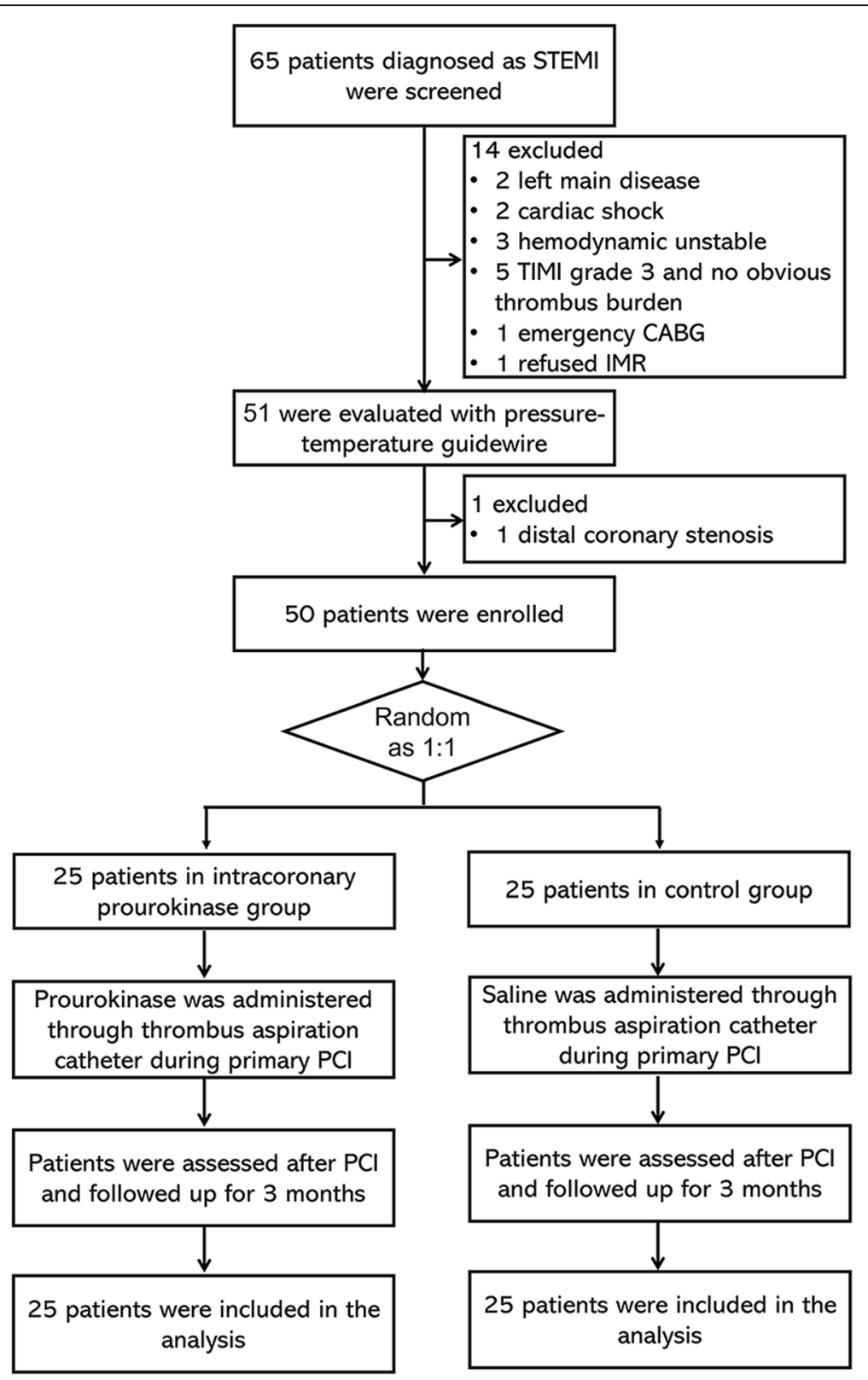

Fig. 1 Study flow

The values of IMR, CFR and FFR were measured by the formulas as follows: IMR $=\mathrm{Pd}^{*} \mathrm{hT}_{\mathrm{mn}}, \mathrm{CFR}=\mathrm{bT}_{\mathrm{mn}} / \mathrm{hT}_{\mathrm{mn}}$, $\mathrm{FFR}=\mathrm{Pd} / \mathrm{Pa}$. The catheter and guidewire sensor location remained in the same position to avoid deviation in the measurement of transit time.

\section{Post- $\mathrm{PCl}$ angiographic assessments}

Through the coronary angiography post-primary PCI, the TIMI [10], corrected TIMI frame count (CTFC) [11] and TIMI myocardial perfusion grade (TMPG) [12] were evaluated by two experienced intervention cardiologists blinded to the assignment of the patients.

\section{Myocardial infarct size and myocardial reperfusion assessment}

Venous blood was collected every $6 \mathrm{~h}$ from all patients after hospital admission, and myocardial injury markers including creatine kinase (CK), creatine kinase isoenzyme-MB (CKMB) and cardiac troponin I (cTnI) were measured, and the peak values of markers were recorded to estimate the infarct size. Besides, all patients were reviewed 12-lead ECG every $10 \mathrm{~min}$ within $60 \mathrm{~min}$ after primary PCI. A decrease in the sum ST-segment elevation by $\geq 70 \%$ was defined as complete ST-segment resolution (STR) and 
was regarded as assessment for myocardial reperfusion after primary PCI.

\section{Cardiac function evaluation}

ECG was performed during hospital admission (within $24 \mathrm{~h}$ ) and repeated at the 3rd month after primary PCI to assess left ventricular ejection fraction (LVEF), left ventricular end-diastolic diameter (LVEDd) and wall motion score index (WMSI). Patients were received twodimensional ventricular volumes, and LVEF were measured using the modified Simpson's rule. And the WMS was measured using a 16-segments model by two cardiologists, each segment was visually analyzed and scored from 1 to $5(1=$ normal, 2 =hypokinetic, $3=$ akinetic, $4=$ dyskinetic, $5=$ aneurysm). WMSI $=$ the total score of each segment score/total number of participating integrals.

\section{Follow up}

After discharge from hospital, all patients were followed up monthly for 3 months by outpatient clinic visiting or by telephone and/or medical questionnaires. The major adverse coronary events (MACEs) and hemorrhagic complications were documented from hospital admission to 3 months post-primary PCI. MACEs included cardiac death, various degrees of heart failure, malignant arrhythmia, new myocardial infarction and target vessel revascularization (TVR).

\section{Study endpoints}

The primary endpoints were IMR, CFR and FFR after $\mathrm{PCI}$, and the secondary endpoints included (1) post-PCI TIMI grade, CTFC, TMPG, peak values of CK, CK-MB and cTnI, and percentage of complete STR, (2) LVEF, LVEDd and WMSI within $24 \mathrm{~h}$ after hospital admission and at the 3rd month post PCI, (3) hemorrhagic complications and MACEs occurred from hospital admission to 3 months post PCI.

\section{Statistical analysis}

The sample size of this study was calculated based on previous studies $[13,14]$. Assuming the IMR in the intracoronary prourokinase group was $30 \mathrm{U}(\mathrm{SD}=10)$ and $40 \mathrm{U}(\mathrm{SD}=13)$ in the control group, with a power of $90 \%$, a two-sided 5\% level of significance $(\alpha)$ and a sample size ratio of $1: 1$, required a sample size of 20 participants in the intracoronary prourokinase group and 20 in control group. Considering a $20 \%$ attrition rate, the sample size was inflated to 50 with 25 participants in each group. Continuous variables were presented as mean with standard deviation (SD) if normally distributed or median and interquartile range (IQR) if non-normally distributed. Normality of continuous variable was determined by the Kolmogorov-Smirnov test. Categorical variables were expressed as absolute values and percentage. Differences between two groups were determined by Student's t-test (for normal distribution values), Mann-Whitney $U$ test (for non-normal distribution values) or Chi-squared test or Fisher's exact test (for categorical values as appropriate.) Two-sided $P$-value $<0.05$ was considered as statistically significant. SPSS 23.0 (SPSS Inc., Chicago, IL, USA) was used for statistical analysis, and GraphPad Prism 7.02 (GraphPad Software Inc., San Diego, CA, USA) was applied to plot graphs.

\section{Results}

\section{Patients' characteristics at baseline}

No difference of demographic or clinical characteristics was found between intracoronary prourokinase group and control group (Table 1). The values of mean ages were $59.48 \pm 14.36$ years and $60.96 \pm 12.56$ years $(P=$ $0.700)$, and the numbers of the male were $21(80.8 \%)$ and $22(88.0 \%)(P=0.440)$ in the intracoronary prourokinase group and control group, respectively. Besides, patients had a mean BMI of $25.69 \pm 2.94 \mathrm{~kg} / \mathrm{m}^{2}$ in intracoronary prourokinase group, and $25.45 \pm 2.89 \mathrm{~kg} /$ $\mathrm{m}^{2}$ in control group $(P=769)$. In addition, the mean levels of SBP were $130.36 \pm 24.31 \mathrm{mmHg}$ and $131.72 \pm$ $24.93 \mathrm{mmHg}(P=0.846)$, and the mean DBPs were $77.76 \pm 15.56 \mathrm{mmHg}$ and $81.92 \pm 18.13 \mathrm{mmHg} \quad(P=$ 0.388 ) in the two groups, respectively. The mean GFR was $91.17 \pm 26.26 \mathrm{ml} / \mathrm{min}$ in intracoronary prourokinase group and was $96.62 \pm 20.49 \mathrm{ml} / \mathrm{min}$ in control group $(P=0.418)$. The information of other clinical characteristics was listed in Table 1.

\section{Patients' angiographic and procedural characteristics}

The angiographic and procedural characteristics were recorded as well, and no difference of angiographic and procedural characteristics was found between the two groups (Table 2). In detail, the number of patients who had infarction of LAD, LCX and RCA were 8 (32.0\%), 3 $(12.0 \%)$ and $14(56.0 \%)$ in intracoronary prourokinase group, and were $10(40.0 \%), 3(12.0 \%)$ as well as 12 $(48.0 \%)$ in control group $(P=0.829)$. There were 4 (16.0\%) patients with thrombus grade 1, 2 (8.0\%) patients with grade 4 , and $19(76.0 \%)$ patients with grade 5 in intracoronary prourokinase group, while there were 1 $(4.0 \%)$ patient with grade $2,3(12.0 \%)$ patients with grade 3, $4(16.0 \%)$ patients with grade 4 as well as $17(68.0 \%)$ patients with grade 5 in control group $(P=0.750)$. The information of other angiographic and procedural characteristics was presented in Table 2.

\section{Outcomes of coronary physiology}

The mean value of IMR was markedly decreased in intracoronary prourokinase group than that in control group (34.56 \pm 7.48 vs. $49.00 \pm 8.98, P<0.001)$ (Fig. $2 \mathrm{a}$ ), 
Table 1 Baseline characteristics

\begin{tabular}{|c|c|c|c|}
\hline Parameters & Intracoronary prourokinase group $(N=25)$ & Control group $(N=25)$ & $P$ value \\
\hline Age, mean $\pm S D$, years & $59.48 \pm 14.36$ & $60.96 \pm 12.56$ & 0.700 \\
\hline Male, No. (\%) & $21(80.8)$ & $22(88.0)$ & 0.440 \\
\hline $\mathrm{BMI}$, mean $\pm \mathrm{SD}, \mathrm{kg} / \mathrm{m}^{2}$ & $25.69 \pm 2.94$ & $25.45 \pm 2.89$ & 0.769 \\
\hline Current smoker, No. (\%) & $12(48.0)$ & $13(52.0)$ & 0.777 \\
\hline Angina history, No. (\%) & $13(52.0)$ & $11(44.0)$ & 0.571 \\
\hline Hypertension, No. (\%) & $17(47.2)$ & $19(52.8)$ & 0.529 \\
\hline Diabetes mellitus, No. (\%) & $8(32.0)$ & $6(24.0)$ & 0.528 \\
\hline Dyslipidemia, No. (\%) & $8(30.0)$ & $5(20.0)$ & 0.333 \\
\hline Heart rate, mean $\pm S D$, bpm & $73.24 \pm 14.22$ & $77.40 \pm 16.32$ & 0.341 \\
\hline $\mathrm{SBP}$, mean $\pm \mathrm{SD}, \mathrm{mmHg}$ & $130.36 \pm 24.31$ & $131.72 \pm 24.93$ & 0.846 \\
\hline $\mathrm{DBP}$, mean $\pm \mathrm{SD}, \mathrm{mmHg}$ & $77.76 \pm 15.56$ & $81.92 \pm 18.13$ & 0.388 \\
\hline Killip grade, No. (\%) & & & 0.465 \\
\hline I & $10(40.0)$ & $14(56.0)$ & \\
\hline$\|$ & $11(44.0)$ & $9(36.0)$ & \\
\hline III & $4(16.0)$ & $2(8.0)$ & \\
\hline Creatinine, mean $\pm S D, \mu \mathrm{mol} / \mathrm{L}$ & $85.32 \pm 28.85$ & $79.56 \pm 16.23$ & 0.389 \\
\hline $\mathrm{GRF}$, mean $\pm \mathrm{SD}, \mathrm{ml} / \mathrm{min}$ & $91.17 \pm 26.26$ & $96.62 \pm 20.49$ & 0.418 \\
\hline $\mathrm{RBC}$, mean $\pm \mathrm{SD}, 10 \wedge 9 / \mathrm{L}$ & $4.54 \pm 0.52$ & $4.51 \pm 0.55$ & 0.845 \\
\hline $\mathrm{NLR}$, mean $\pm \mathrm{SD}$ & $8.20 \pm 5.53$ & $8.19 \pm 6.94$ & 0.996 \\
\hline $\mathrm{PLT}$, mean $\pm \mathrm{SD}, 10^{\wedge} 9 / \mathrm{L}$ & $191.53 \pm 91.73$ & $220.92 \pm 46.34$ & 0.159 \\
\hline$M P V$, mean $\pm S D, f L$ & $7.70 \pm 2.70$ & $8.43 \pm 1.89$ & 0.222 \\
\hline \multicolumn{4}{|l|}{ Medications prior to $\mathrm{PCl}$, No.(\%) } \\
\hline Aspirin & $25(100.0)$ & $25(100.0)$ & 1.000 \\
\hline Ticagrelor & $25(100.0)$ & $25(100.0)$ & 1.000 \\
\hline Statins & $25(100.0)$ & $25(100.0)$ & 1.000 \\
\hline Heparin & $25(100.0)$ & $25(100.0)$ & 1.000 \\
\hline Ilb/Illa inhibitor & $18(72.0)$ & $14(56.0)$ & 0.239 \\
\hline Intravenous nitroglycerin & $15(60.0)$ & $18(72.0)$ & 0.370 \\
\hline \multicolumn{4}{|l|}{ Medications at discharge, No.(\%) } \\
\hline ACEI & $16(64.0)$ & $20(80.0)$ & 0.208 \\
\hline B-blocker & $14(56.0)$ & $18(72.0)$ & 0.239 \\
\hline Statins & $25(100.0)$ & $25(100.0)$ & 1.000 \\
\hline DAPT & $25(100.0)$ & $25(100.0)$ & 1.000 \\
\hline
\end{tabular}

Differences between two groups were determined by Student's t-test, Mann-Whitney U test, Chi-squared test or Fisher's exact test, as appropriate. SD standard deviation, $B M I$ body mass index, SBP systolic blood pressure, $D B P$ diastolic blood pressure, GRF glomerular filtration rate, RBC red blood count, NLR neutrophiltolymphocyte ratio, PLT platelet count, MPV mean platelet volume, $P C l$ percutaneous coronary intervention, ACEl angiotension-converting enzyme, DAPT dual anti-platelet therapy

however, the mean CFR $(2.01 \pm 0.32$ vs. $1.88 \pm 0.23, P=$ $0.267)$ (Fig. 2b) and mean FFR $(0.89 \pm 0.05$ vs. $0.87 \pm$ $0.04, P=0.121$ ) (Fig. 2c) were of no difference between the two groups.

Outcomes of angiographic assessment, myocardial infarct size and myocardial reperfusion

There were more patients with higher grades of TMPG in intracoronary prourokinase group compared with control group $(P=0.024)$ (Table 3$)$. In addition, the mean CK peak value $(P=0.028), C K-M B$ peak value $(P=0.016)$ and cTnI peak value $(P=0.032)$ were all reduced in intracoronary prourokinase group compared with control group. Moreover, the percentage of patients who had complete STR was increased in intracoronary prourokinase group than that in control group $(P=$ $0.005)$. However, no difference of TIMI grade $(P=0.440)$ or CTFC ( $P=0.235)$ was found between the two groups. 
Table 2 Angiographic and procedural characteristics

\begin{tabular}{|c|c|c|c|}
\hline Parameters & Intracoronary prourokinase group $(N=25)$ & Control group $(N=25)$ & $P$ value \\
\hline Infarction related artery, №. (\%) & & & 0.829 \\
\hline LAD & $8(32.0)$ & $10(40.0)$ & \\
\hline LCX & $3(12.0)$ & $3(12.0)$ & \\
\hline RCA & $14(56.0)$ & $12(48.0)$ & \\
\hline No. of diseased vessels, No. (\%) & & & 0.776 \\
\hline 1 & $4(16.0)$ & $3(12.0)$ & \\
\hline 2 & $5(20.0)$ & $7(28.0)$ & \\
\hline 3 & $16(64.0)$ & $15(60.0)$ & \\
\hline Thrombus grade before $\mathrm{PCl}$, No. (\%) & & & 0.750 \\
\hline 1 & $4(16.0)$ & $0(0.0)$ & \\
\hline 2 & $0(0.0)$ & $1(4.0)$ & \\
\hline 3 & $0(0.0)$ & $3(12.0)$ & \\
\hline 4 & $2(8.0)$ & $4(16.0)$ & \\
\hline 5 & $19(76.0)$ & $17(68.0)$ & \\
\hline Collateral vessel, No. (\%) & $15(60.0)$ & $17(68.0)$ & 0.556 \\
\hline Temporary pacemaker, No. (\%) & $2(8.0)$ & $3(12.0)$ & 0.637 \\
\hline Number of stents, mean \pm SD & $1.12 \pm 0.33$ & $1.08 \pm 0.28$ & 0.646 \\
\hline Stent diameter, mean $\pm S D, m m$ & $3.01 \pm 0.51$ & $3.09 \pm 0.55$ & 0.590 \\
\hline Stent length, mean $\pm S D, m m$ & $23.48 \pm 4.49$ & $22.84 \pm 6.57$ & 0.690 \\
\hline Stent release pressure, mean $\pm S D$, atm & $14.12 \pm 3.59$ & $12.72 \pm 4.34$ & 0.220 \\
\hline Number of inflations, mean \pm SD & $3.96 \pm 1.54$ & $4.79 \pm 2.23$ & 0.134 \\
\hline Pre-dilation pressure, mean $\pm \mathrm{SD}$, atm & $12.16 \pm 3.05$ & $11.48 \pm 2.69$ & 0.408 \\
\hline Post dilation, No.(\%) & $15(60)$ & $13(52)$ & 0.569 \\
\hline Post-dilation times, median (IQR) & $3(1-4)$ & $3(2-5)$ & 0.918 \\
\hline Trans-radial or ulnar artery, No.(\%) & $25(100.0)$ & $25(100.0)$ & 1.000 \\
\hline
\end{tabular}

Differences between two groups were determined by Student's t-test, Mann-Whitney $\mathrm{U}$ test, Chi-squared test or Fisher's exact test, as appropriate. FMC first medical contact, $L A D$ left anterior descending, $L C X$ left anterior descending, $R C A$ right coronary artery, $P C I$ percutaneous coronary intervention, $S D$ standard deviation, IQR interquartile range
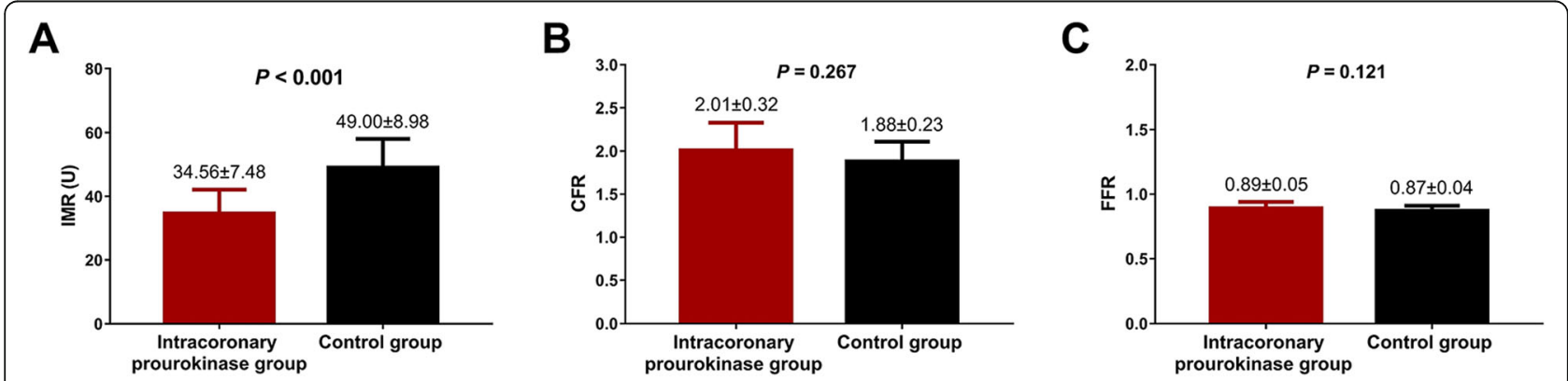

Fig. 2 Coronary physiology assessments results. The IMR in intracoronary prourokinase group was reduced compared with control group (a), while no difference of CFR (b) or FFR (c) was found between the two groups. Comparison between the two groups was determined by t-test. $P$ value $<0.05$ was considered as statistically significant. IMR, index of microcirculatory resistance; CFR, coronary flow reserve; FFR, fractional flow reserve 
Table 3 Angiographic outcomes, myocardial infarct size and myocardial reperfusion post PCl

\begin{tabular}{|c|c|c|c|}
\hline Parameters & Intracoronary prourokinase group $(N=25)$ & Control group $(N=25)$ & $P$ value \\
\hline TIMl grade, No. (\%) & & & 0.440 \\
\hline 0 & $0(0.0)$ & $0(0.0)$ & \\
\hline 1 & $0(0.0)$ & $0(0.0)$ & \\
\hline 2 & $3(12.0)$ & $5(20.0)$ & \\
\hline 3 & $22(88.0)$ & $20(80.0)$ & \\
\hline TMPG, No. (\%) & & & 0.024 \\
\hline 0 & $0(0.0)$ & $0(0.0)$ & \\
\hline 1 & $0(0.0)$ & $1(4.0)$ & \\
\hline 2 & $4(16.0)$ & $14(56.0)$ & \\
\hline 3 & $21(84.0)$ & $10(40.0)$ & \\
\hline$C T F C$, mean $\pm S D$, frames & $16.68 \pm 7.26$ & $19.05 \pm 6.69$ & 0.235 \\
\hline CK peak value, mean $\pm S D, U / L$ & $1159.12 \pm 617.89$ & $1661.18 \pm 1079.60$ & 0.028 \\
\hline CK-MB peak value, mean $\pm S D, U / L$ & $123.10 \pm 31.09$ & $181.56 \pm 112.85$ & 0.016 \\
\hline cTnl peak value, mean $\pm S D$, ng/L & $38.83 \pm 12.53$ & $51.71 \pm 26.32$ & 0.032 \\
\hline Complete STR, No. (\%) & $24(96.0)$ & $16(64.0)$ & 0.005 \\
\hline
\end{tabular}

Differences between two groups were determined by Student's t-test, Mann-Whitney U test, Chi-squared test or Fisher's exact test, as appropriate. TIMI thrombolysis in myocardial infarction, TMPG TIMI myocardial perfusion grade, CTFC corrected TIMI frame count, SD standard deviation, CK creatine kinase, CK-MB creatine kinase isoenzyme-MB, STR ST segment resolution

\section{Outcomes of cardiac function}

The mean values of 1-day LVEF $(P=0.899)$, LVEDd $(P=0.938)$ and WMSI $(P=0.724)$ post PCI were similar between intracoronary prourokinase group and control group (Table 4). However, post PCI, the mean 3-month LVEF was elevated $(P=0.017)$, while LVEDd $(P=0.013)$ and WMSI $(P=0.015)$ were decreased intracoronary prourokinase group compared with control group.

\section{Hemorrhagic complications and MACEs}

Post PCI, no case of intracranial hemorrhage, hematemesis, hemoptysis, hematuria, hemorrhage of puncture site was found in both intracoronary prourokinase group and control group (Table 5). As for the other hemorrhagic complications that were recorded, no difference regarding the number of patients who had dermatorrhagia $(P=1.000)$ or gingival bleeding $(P=1.000)$ was found between the two groups. In detail, there were
1 (4.0\%) patient with dermatorrhagia and 2 (8.0\%) patients with gingival bleeding in intracoronary prourokinase group, and in control group, there was 1 (4.0\%) patient who had gingival bleeding. With respect to MACEs post PCI, no difference of the number of total MACEs was found between the tw o groups $(P=0.157)$. Additionally, no cases of cardiac death, TVR or stroke were found in the two groups, and the percentage of total MACE $(P=0.157)$, patients who had stent thrombosis $(P=1.000)$, heart failure $(P=0.667)$ and malignant arrhythmia $(P=0.552)$ were similar between the two groups (Table 6).

\section{Discussion}

There remains several problems to be resolved in STEMI treatment, including the choice of performing PCI only on the culprit artery or in multiple arteries, and the reduction of time delay before PCI treatment,

Table 4 Cardiac function

\begin{tabular}{llll}
\hline & Intracoronary prourokinase group $(N=25)$ & Control group $(N=25)$ & $P$ value \\
\hline 1-day LVEF, mean $\pm S D, \%$ & $55.81 \pm 5.86$ & $55.60 \pm 5.69$ & 0.899 \\
1-day LVEDd, mean $\pm S D, c m$ & $4.80 \pm 0.29$ & $4.81 \pm 0.32$ & 0.938 \\
1-day WMSI, mean $\pm S D$ & $2.12 \pm 0.23$ & $2.14 \pm 0.24$ & 0.724 \\
3-month LVEF, mean $\pm S D, \%$ & $60.84 \pm 2.29$ & $59.18 \pm 2.44$ & 0.017 \\
3-month LVEDd, mean $\pm S D, c m$ & $4.73 \pm 0.19$ & $4.89 \pm 0.25$ & 0.013 \\
3-month WMSI, mean \pm SD & $1.84 \pm 0.16$ & $1.95 \pm 0.15$ & 0.015 \\
\hline
\end{tabular}

Differences between two groups were determined by Student's t-test. LVEF left ventricular ejection fraction, LVEDd left ventricular end-diastolic diameters, WMSI wall motion score index 
Table 5 Hemorrhagic complications during 3-month follow up

\begin{tabular}{llll}
\hline Items & $\begin{array}{l}\text { Intracoronary } \\
\text { prourokinase } \\
\text { group }(N=25)\end{array}$ & $\begin{array}{l}\text { Control group } \\
(N=25)\end{array}$ & $P$ value \\
\hline $\begin{array}{l}\text { Intracranial hemorrhage, } \\
\text { No. (\%) }\end{array}$ & $0(0.0)$ & $0(0.0)$ & - \\
Hematemesis, No. (\%) & $0(0.0)$ & $0(0.0)$ & - \\
Hemoptysis, No. (\%) & $0(0.0)$ & $0(0.0)$ & - \\
Hematuria, No. (\%) & $0(0.0)$ & $0(0.0)$ & - \\
$\begin{array}{l}\text { Dermatorrhagia, No. (\%) } \\
\text { Hemorrhage of puncture }\end{array}$ & $0(0.0)$ & $0(0.0)$ & 1.000 \\
site, No. (\%) & $0(0.0)$ & - \\
Gingival bleeding, No. (\%) & $2(8.0)$ & $1(4.0)$ & 1.000 \\
\hline
\end{tabular}

Differences between two groups were determined by Fisher's exact test

among which the latter is more urgent [15]. Thus, boosting efficacy and safety of PCI in STEMI is constantly a major concern in clinical practice. In addition, the use of prourokinase in myocardial infarction including STEMI has been tested in various clinical trials and studies, which altogether present a good efficacy and safety of prourokinase as a thrombolytic agent $[16,17]$. Therefore, we performed this randomized clinical trial which evaluated the efficacy and safety of intracoronary prourokinase during PCI for STEMI treatment, and the main findings were as follows: 1) IMR was decreased in intracoronary prourokinase group compared with control group; 2) TMPG, CK peak value, CK-MB peak value, cTnI and STR were more satisfactory in intracoronary prourokinase group than those in control group; 3) the cardiac function including LVEF, LVEDd and WMSI were better in intracoronary prourokinase group compared with control group; 4) no difference regarding hemorrhagic AEs and MACE incidences was found between the two groups.

The evidence of prourokinase in treating STEMI is still lacking, there are even insufficient studies regarding the prourokinase in treating myocardial infarction. A recent phase IV clinical trial evaluating efficacy and tolerance

Table 6 MACE during 3-month follow up

\begin{tabular}{llll}
\hline Items & $\begin{array}{l}\text { Intracoronary } \\
\text { prourokinase } \\
\text { group }(N=25)\end{array}$ & $\begin{array}{l}\text { Control groups } \\
(N=25)\end{array}$ & $P$ value \\
\hline Total MACE, No. (\%) & $3(12.0)$ & $7(28.0)$ & 0.157 \\
$\quad$ Cardiac death, No. (\%) & $0(0.0)$ & $0(0.0)$ & - \\
Stent thrombosis, No. (\%) & $0(0.0)$ & $1(4.0)$ & 1.000 \\
TVR, No. (\%) & $0(0.0)$ & $0(0.0)$ & - \\
Heart failure, No. (\%) & $2(8.0)$ & $4(16.0)$ & 0.667 \\
Malignant arrhythmia, & $1(4.0)$ & $2(8.0)$ & 0.552 \\
No. (\%) & & & - \\
Stroke, No. (\%) & $0(0.0)$ & $0(0.0)$ & - \\
\hline
\end{tabular}

Differences between two groups were determined by Fisher's exact test. MACE major adverse cardiac events, TVR target vessel revascularization of prourokinase injection in STEMI patients reveals a successful reperfusion rate of $85.4 \%$ in patients, which indicates a good efficacy [6]. And in the study conducted in STEMI patients who receive intracoronary administration of prourokinase through balloon catheter during primary PCI illuminates that the proportions of patients who achieve complete ST-segment resolution, reduced levels of serum CK, CK-MB and TnI are higher than those in patients treated with PCI alone [16]. Another randomized controlled trial reveals more cases of opened infarct-related artery on arrival in the catheterization laboratory and better TIMI frame count in patients receiving PCI with prourokinase than patients receiving only PCI; in addition, at 1 -year followup, this study also elucidates that patients receiving PCI with prourokinase present with a trend of less incidence of MACE and re-admission to hospital compared with patients treated by PCI alone [17]. In this randomized controlled study, we found that the STEMI patients receiving intracoronary prourokinase during PCI presented with better improvement of IMR compared with patients receiving only $\mathrm{PCI}$, and the TMPG, CK peak value, CKMB peak value, cTnI, STR as well as the 3-month LVEF, LVEDd and WMSI were also better compared with patients who received only $\mathrm{PCI}$, which were in accordance with the previous trials. And here are several explanations to our findings: the benefits in intracoronary prourokinase group might be derived from that prourokinase is a highly effective fibrin-specific thrombolytic agent, which enhanced the patent efficiency in STEMI patients and thus improved the occlusion of coronary artery compared with only using saline in PCI, therefore the reperfusion of the cardiac muscle was universally more efficient in intracoronary prourokinase group than that in control group, resulting in a better angiographic outcomes, myocardial infarct size reduction, myocardial reperfusion and cardiac function recovery in STEMI patients. In addition, the results in our study also revealed that there was no difference regarding CFR and FFR between the two groups, while, the IMR was notable distinct between the two groups. This result could be caused by the following reasons: first, the sample size in our study was relatively small, which reduced the statistical power to some extent, and subsequently resulted in that the levels of FFR and CFR were numerically but not significantly different between the two groups. Second, the function indicated by the three indexes were distinctive, IMR mainly indicated the microcirculatory function, FFR predominantly indicated the function of the epicardial vascular, while CFR indicated the overall function of coronary artery.

Cardiovascular and hemorrhagic complications are the most common adverse events post PCI treatment, what's more important is that they are also fatal complications 
in STEMI patients, for instance, the atrial fibrillation, heart failure and stroke caused by intracranial hemorrhage [18-23]. In a previous clinical trial, the proportions of deaths, post-infarction angina, re-infarction/ reocclusion and emergency revascularization were 4.48, 15.2, 4.21, and $8.27 \%$ in STEMI patients treated by prourokinase during PCI [6]. In another randomized clinical trial, there is no differences of hemorrhagic complications and MACE incidences between patients treated by prourokinase during $\mathrm{PCI}$ and patients treated by only PCI, which is in accordance with our results [16]. A multicenter randomized clinical trial elucidates that although not statistically significant, there seems to be less MACEs and readmissions in patients treated with prourokinase during PCI compared with patients receiving PCI alone [17]. In this trial, we did not find any difference between the two groups with respect to the incidence of hemorrhagic complications or MACEs, which indicated that the use of prourokinase in PCI for STEMI patients did not lead to extra complications compared with a single PCI.

Limitations existed in this trial, which included: 1) the follow up time was relatively short to observe the longterm efficacy and safety of intracoronary prourokinase during PCI in STEMI patients; 2) the study design of a non-blinded method of this trial might cause observer bias; 3) the sample size of this trial was small, which may reduce the statistical power; 4) the level of IMR at baseline was not recorded, which resulted in that the change of microvascular function assessed by IMR from baseline to follow ups could not be evaluated. Therefore, a single/double/triple-blinded clinical trial with a larger sample size, prolonged follow up duration and assessment of baseline microvascular function is needed in the future.

\section{Conclusions}

In conclusion, intracoronary prourokinase during PCI is more efficient and equally tolerant compared with PCI alone in treating STEMI patients.

\footnotetext{
Abbreviations

STEMI: ST-segment elevation myocardial infarction; PCl: Percutaneous coronary intervention; MACEs: Major adverse coronary events; IMR: Index of microcirculatory resistance; CFR: Coronary flow reserve; FFR: Fractional flow reserve; TMPG: Thrombolysis in myocardial infarction myocardial perfusion grade; CK: Creatine kinase; CK-MB: CK isoenzyme-MB; STR: ST-segment resolution; LVEF: Left ventricular ejection fraction; WMSI: Wall motion score index; LVEDd: Left ventricular end-diastolic diameter;

ECG: Electrocardiograph; SBP: Systolic blood pressure; HR: Heart rate; TIMI: Thrombolysis in myocardial infarction; CTFC: Corrected TIMI frame count; TMPG: TIMI myocardial perfusion grade; TVR: Target vessel revascularization; SD: Standard deviation; IQR: Interquartile range
}

\section{Authors' contributions}

YW and XF conceived and designed the study. YW, QF, XG and WF drafted the manuscript. $X F, G H$ and $Y J$ revised the manuscript. QF, XG, GH, WF and $Y J$ responsible for data collection and performed the statistical analysis. All authors read and approved the final manuscript.

\section{Funding}

None.

\section{Availability of data and materials}

All data generated or analysed during this study are included in this published article.

\section{Ethics approval and consent to participate}

The study protocol was approved by the Ethics Committee of the Second Hospital of Hebei Medical University, and the study was conducted in accordance with the Declaration of Helsinki and Good Clinical Practice guidelines. Written informed consents were provided by all study participants.

\section{Consent for publication}

Not applicable.

\section{Competing interests}

The authors declare that they have no competing interests.

\section{Author details}

${ }^{1}$ Department of Cardiology, The Second Hospital of Hebei Medical University, 215 West Heping Road, Shijiazhuang 050000, China. ${ }^{2}$ Department of Cardiology, Handan Central Hospital, Handan 056000, China.

Received: 16 April 2019 Accepted: 12 June 2020

Published online: 26 June 2020

\section{References}

1. Windecker S, Bax JJ, Myat A, Stone GW, Marber MS. Future treatment strategies in ST-segment elevation myocardial infarction. Lancet. 2013; 382(9892):644-57.

2. Bhatt DL. Percutaneous coronary intervention in 2018. Jama. 2018;319(20): 2127-8.

3. Pedersen F, Butrymovich V, Kelbaek H, Wachtell K, Helqvist S, Kastrup J, et al Short- and long-term cause of death in patients treated with primary PCI for STEMI. J Am Coll Cardiol. 2014;64(20):2101-8.

4. Tomasi S, Sarmientos P, Giorda G, Gurewich V, Vercelli A. Mutant prourokinase with adjunctive C1-inhibitor is an effective and safer alternative to tPA in rat stroke. PLoS One. 2011;6(7):e21999.

5. Gurewich V, Pannell R, Simmons-Byrd A, Sarmientos P, Liu JN, Badylak SF. Thrombolysis vs. bleeding from hemostatic sites by a prourokinase mutant compared with tissue plasminogen activator. J Thromb Haemost. 2006;4(7): 1559-65.

6. Zhao L, Zhao Z, Chen X, Li J, Liu J, Li G, et al. Safety and efficacy of prourokinase injection in patients with ST-elevation myocardial infarction: phase IV clinical trials of the prourokinase phase study. Heart Vessel. 2018; 33(5):507-12.

7. Task Force M, Montalescot G, Sechtem U, Achenbach S, Andreotti F, Arden C, et al. 2013 ESC guidelines on the management of stable coronary artery disease: the Task Force on the management of stable coronary artery disease of the European Society of Cardiology. Eur Heart J. 2013;34(38): 2949-3003.

8. Neumann FJ, Sousa-Uva M, Ahlsson A, Alfonso F, Banning AP, Benedetto U, et al. 2018 ESC/EACTS guidelines on myocardial revascularization. Eur Heart J. 2019;40(2):87-165.

9. Sianos G, Papafaklis MI, Serruys PW. Angiographic thrombus burden classification in patients with ST-segment elevation myocardial infarction treated with percutaneous coronary intervention. J Invasive Cardiol. 2010; 22(10 Suppl B):6B-14B

10. Gibson CM, de Lemos JA, Murphy SA, Marble SJ, CH MC, Cannon CP, et al. Combination therapy with abciximab reduces angiographically evident thrombus in acute myocardial infarction: a TIMI 14 substudy. Circulation. 2001;103(21):2550-4. 
11. Palmer S, Layland J, Carrick D, Williams PD, Judkins C, Gong FF, et al. The index of microcirculatory resistance Postpercutaneous coronary intervention predicts left ventricular recovery in patients with Thrombolyzed ST-segment elevation myocardial infarction. J Interv Cardiol. 2016;29(2):146-54.

12. van't Hof AW, Liem A, Suryapranata H, Hoorntje JC, de Boer MJ, Zijlstra F. Angiographic assessment of myocardial reperfusion in patients treated with primary angioplasty for acute myocardial infarction: myocardial blush grade. Zwolle myocardial infarction study group. Circulation. 1998;97(23):2302-6.

13. Fu Y, Gu XS, Hao GZ, Jiang YF, Fan WZ, Fan YM, et al. Comparison of myocardial microcirculatory perfusion after catheter-administered intracoronary thrombolysis with anisodamine versus standard thrombus aspiration in patients with ST-elevation myocardial infarction. Catheter Cardiovasc Interv. 2019;93(S1):839-45.

14. Wang K, Zhang J, Zhang N, Shen Y, Wang L, Gu R, et al. Combined primary $\mathrm{PCl}$ with multiple thrombus burden reduction therapy improved cardiac function in patients with acute anterior myocardial infarction. Int Heart J. 2019;60(1):27-36.

15. Bates ER, Tamis-Holland JE, Bittl JA, O'Gara PT, Levine GN. PCl strategies in patients with ST-segment elevation myocardial infarction and multivessel coronary artery disease. J Am Coll Cardiol. 2016;68(10):1066-81.

16. Geng W, Zhang Q, Liu J, Tian X, Zhen L, Song D, et al. A randomized study of prourokinase during primary percutaneous coronary intervention in acute ST-segment elevation myocardial infarction. J Interv Cardiol. 2018; 31(2):136-43.

17. Han YL, Liu JN, Jing QM, Ma YY, Jiang TM, Pu K, et al. The efficacy and safety of pharmacoinvasive therapy with prourokinase for acute ST-segment elevation myocardial infarction patients with expected long percutaneous coronary intervention-related delay. Cardiovasc Ther. 2013;31(5):285-90.

18. Moss AJ, Shah ASV, Zuling ET, Freeman M, Newby DE, Adamson PD, et al. Left ventricular thrombus in patients after primary percutaneous coronary intervention for ST-elevation myocardial infarction: 1year clinical outcomes. Am J Med. 2019;132(8):964.

19. Abolahrari-Shirazi S, Kojuri J, Bagheri Z, Rojhani-Shirazi Z. Effect of exercise training on heart rate variability in patients with heart failure after percutaneous coronary intervention. J Biomed Phys Eng. 2019:9(1):97-104.

20. Bei WJ, Wang K, Li HL, Guo XS, Guo W, Abuduaini T, et al. Safe hydration to prevent contrast-induced acute kidney injury and worsening heart failure in patients with renal insufficiency and heart failure undergoing coronary angiography or percutaneous coronary intervention. Int Heart J. 2019;60(2): $247-54$

21. Naik BI, Keeley EC, Gress DR, Zuo Z. Case scenario: a patient on dual antiplatelet therapy with an intracranial hemorrhage after percutaneous coronary intervention. Anesthesiology. 2014;121(3):644-53.

22. Wang Y, Zhao HW, Wang CF, Fan CY, Zhang XJ, Zhu Y, et al. Efficacy and safety of bivalirudin during percutaneous coronary intervention in highbleeding-risk elderly patients with chronic total occlusion: a prospective randomized controlled trial. Catheter Cardiovasc Interv. 2019;93(S1):825-31.

23. Fan ZG, Zhang WL, Xu B, Ji J, Tian NL, He SH. Comparisons between ticagrelor and clopidogrel following percutaneous coronary intervention in patients with acute coronary syndrome: a comprehensive meta-analysis. Drug Design Dev Ther. 2019;13:719-30.

\section{Publisher's Note}

Springer Nature remains neutral with regard to jurisdictional claims in published maps and institutional affiliations.

Ready to submit your research? Choose BMC and benefit from:

- fast, convenient online submission

- thorough peer review by experienced researchers in your field

- rapid publication on acceptance

- support for research data, including large and complex data types

- gold Open Access which fosters wider collaboration and increased citations

- maximum visibility for your research: over $100 \mathrm{M}$ website views per year

At $\mathrm{BMC}$, research is always in progress.

Learn more biomedcentral.com/submissions 